\title{
Über eine neue Verfälschung der Preißelbeeren.
}

\author{
Von \\ W. Rothe. \\ Mitteilung aus der Statlichen Anstalt zur Untersuchung von Nahrungs- \\ nod Genufmitteln sowie Gebranchsgegenständen für den Landespolizei- \\ bezirk Berlin.
}

[Eingegangen am 15. Dezember 1916.]

Über verfälschte PreiBelbeeren ist im Schrifttum bereits des öfteren berichtet worden. Griebel ${ }^{1}$ ) beschrieb die Verfälschung durch Moosbeeren (Vaccinium oxycoccos L.) Solereder ${ }^{2}$ ) die mit den Früchten der Bärentraube (Arctostaphylos uva ursi Spreng.). In beiden Fällen handelte es sich also um Pflanzen, die mit der Preißelbeere (Vaccinium vitis idaea L.) zur Familie der Ericaceen gehören. In der folgenden kurzen Mitteilung soll eine Verfälschung mit den Früchten einer mit der Preißelbeere in keinem verwandtschaftlichen Verbältnis stehenden Pflanze von ganz anderer Wuchsform besprochen werden. Es liegt dabei ein allerdings recht plumper Betrug vor, der verhältnismäßig leicht auffällt; dennoch erschien es zweckmäßig, die hier gemachten Beobachtungen bekanntzugeben, um den jetzt im Kriege besonders stark beschäftigten Fachgenossen zeitraubende Nachforschungen zu ersparen. Im Herbst 1916 wurden aus der Bevölkerung bei der Polizei in westlichen Vororten Berlins mehrfach PrelBelbeeren eingeliefert, denen, wie schon dem kundigen Laien erkennbar war, fremde Beeren beigemengt waren, und zwar in Mengen von $50-60 \%$. In der Ware fielen sofort neben normalen Preißelbeeren gröfere dunkelrote eiförmige bis runde beerenartige Früchte auf, die sich als Steinfrüchte des Schneeballs (Viburnum opulus L.) erwiesen. Auch gelangte aus derartig verfälschten Preißelbeeren bereitetes Kompott zur Einlieferung, das einen widerlichen und bitteren Geschmack hatte.

Die Unterschiede zwischen den Steinfrüchten des Schneeballs und den Preißelbeeren sind im wesentlicheo folgende: Die Preißelbeeren, besonders die größeren Exemplare sind nicht völlig rund, sondern zeigen Abplattungen am Scheitel und am Ansatz des Stiels. Die Farbe ist scharlachrot, bisweilen an unreifen Exemplaren mit belleren bis weißlichen Stellen. Am Scheitel sind Reste der vier Kelchblätter vorhanden, die innen die trichterförmigen Ansatzstellen des Griffels einschließen. Manchmal findet man noch den kurzen dicken Fruchtstiel. Vor allem ist darauf hinzuweisen, daß die Preißelbeere eine typische Beere im botanisch-morphologischen Sinne, d. h. eine fleischige Frucht mit mebreren Samen ist.

Die Frucht des Schneeballs sieht dagegen nur äußerlich wie eine Beere aus; in Wirklichkeit handelt es sich um eine Steinfrucht vom botanisch-morphologischen Standpunkt, d. h. um eine fleisehige Frucht mit einem einzigen Samen. Sie mißt bei Viburnum opulus $L_{\text {., }}$ der bei uns häufigeren Art, die hier allein in Frage kommt, im Durchmesser bis $75 \mathrm{~mm}$, ist vielfach nicht kugelig, sondern mehr eiförmig und beì den vorliegenden Verfälschungen in noch nicht völlig reifem Zustande tief dunkelrot, später schwärzlich gefärbt. Am Scheitel trägt sie fast immer noch einen geringen bräunen vertrockneten Rest der Biütenteile. Von den dicken Fruchtstielen waren in den hier zur Beobachtung gelangten Fällen vielfach noch Teile vorhanden, vereinzelte

1) Diese Zeitschrift 1909, 17, 65.

2) Diese Zeitschrift 1916, .81, 352 . 
Früchte hingen noch in den doldigen Fruchtständen zusammen. Das auffallendste Erkennungsmerkmal der Schneeballfrüchte sind die großen, weißgelben, flachen, in der Mitte der beiden Flachseiten etwas gekielten, schwach berzförmigen Steine, die fast die ganze Frucht in zwei Hälften teilen.

Zum SchluB sei noch auf die Entstehung der Schneeballfrüchte hingewiesen. Der Fruchtknoten, der einen kurzen dreiteiligen Griffel trägt, ist ursprünglich dreifächrig mit drei Fruchtblättern, die zwei Samenanlagen tragen. Durch Fehlschlagen der übrigen Teile kommt aber nur ein Fruchtblatt mit einer Samenanlage zur Ausbildung. Es entsteht somit die äuBerlich beerenartige Steinfrucht. Erwähnt sei noch, daß ich ausnahmsweise Samen fand, die infolge von Rückbildungen dreikantig waren.

\title{
Organisches Nichtfett und Stickstoffsubstanz der Fleischwaren.
}

\author{
Von \\ E. Feder aus Aachen \\ z. Zt. Stabsapotheker in Coblenz.
}

[Eingegangen am 23. Dezember 1916.]

Vor kurzem veröffentlichten C. Bauman n und J. GroBfeld ${ }^{1}$ ) in dieser Zeitschrift eine Arbeit, welche mir Anlab zur Stellungnahme gibt. Ich habe nicht etwa den Wassergehalt der Fleischwaren zu einem beliebigen, aber „möglichst konstanten anderen Bestandteil des Fleisehes in Beziehung gebracht", sondern zum Träger des Wassergehaltes, d. h. zum organischen Nichtfett. Bereits in meiner ersten Veröfentlichung erwähnte ich auf Grund von Literaturangaben und eigener Versuche, dak die Werte für das organische Nichtfett und die Stickstoffsubstanz nicht zusammenfallen, sondern vielfach nieht unerheblich - was im Hinblick auf das Vorhandensein stickstofffreier Extraktivstoffe ja schon naheliegend scheint - auseinandergehen. C. Baumann und J. Grobfeld suchen nun an die Stelle des organischen Nichtfettes den nach Kjeldah $\mathrm{K}$ bestimmten Stickstoff zu setzen; als Neuerung schlagen sie also eine scheinbar unerhebliche Abänderung meiner Methode vor. Sie fiühren für ihren Vorschlag zunächst praktische Gründe an, so die geringe Haltbarkeit des Fleisches bezw. den Wasserverlust beim Stehen. Dieser hat aber mit der Ausführung nach der einen oder anderen Arbeitsweise nichts zu tun, da die Art der Wasserbestimmung in beiden Fällen dieselbe ist. Weiter zweifle ich nicht daran, daß die Genauigkeit der Untersuchungsergebnisse bei strenger Befolgung der von mir angegebenen Arbeitsweise eine größere ist, als bei der Ausführung der Abänderungsvorschläge. Ich habe 30 Doppelbestimmungen für den Wassergehalt von Fleisch bekanntgegeben ${ }^{2}$ ), bei welchen ich Unterschiede von 0,02-0,36\% gefunden habe. Die Extraktion des Fettes nach Soxhlet ist bekanntlich bei Fleisch eine recht genaue und gleicht in der Regel die bei der Wasserbestimmung gefundenen geringen Unterschiede noch aus: Wo mehr Wasser festgestellt wurde, wird entsprechend weniger Fett gefunden und umgekehrt. Liegt also grundsätzlıch kein Ánlaß zu einer Änderung der Arbeitsweise vor, so erst reeht nicht zugunsten eines Vorsehlages, dessen Befolgung, wie ich auch weiter unten noch zeigen werde, durchaus keine Gewähr für richtige Ergebnisse liefert. Der Wassergehalt wird nach meinem Vorschlage in $10 \mathrm{~g}$ Substanz ermittelt; eine und

1) Diese Zeitschrift 1916, 32, 489.

$\left.{ }^{2}\right)$ Chem.-Ztg. 1914, 38, 709. 